\title{
Diversidad de helechos y licofitas del Parque Nacional Calilegua, provincia de Jujuy, Argentina
}

\author{
MARÍA ALEJANDRA GANEM ${ }^{1}$, JUAN PABLO RAMOS GIACOSA ${ }^{2,3}$, MARÍA LUJÁN LUNA²,4, \\ MARCELO DANIEL ARANA ${ }^{5}$, ALICIA ROTMAN ${ }^{1}$, OSVALDO AHUMADA ${ }^{1}$, ELÍAS RAMÓN DE \\ LA SOTA ${ }^{2,3}$ y GABRIELA ELENA GIUDICE ${ }^{2}$
}

\begin{abstract}
Summary: Diversity of ferns and lycophytes from Calilegua National Park, Jujuy Province Argentina. The biogeographic province of the "Yungas" is considered by the UNESCO as a Biosphere Reserve. In this zone, Calilegua National Park is one of the "cores" of the Yungas, where ferns and lycophytes grow as epiphytic, terrestrial or saxicoulous in different environments. The aim of this study is to make known the ferns and lycophytes that inhabit in Calilegua National Park, in order to provide information on Yungas biodiversity. For this purpose, 5 field trips were performed during december-May 2007-2011. Voucher specimens were deposited in the following herbaria: JUA, LP and RCV. Other herbaria and specific bibliography were also consulted. According to this study 103 taxa (species and varieties) of ferns and lycophytes inhabit in Calilegua National Park, grouped in 18 families and 43 genera. Six species are first recorded for the Province of Jujuy. Nomenclatural updates and keys for taxa identification are also given.
\end{abstract}

Key words: Biodiversity, Calilegua National Park, ferns, lycophytes, Yungas.

Resumen: La provincia biogeográfica de las Yungas es considerada por la UNESCO como una de las Reservas de la Biosfera. El Parque Nacional Calilegua es uno de los "core" de estas Yungas, donde los helechos y licofitas crecen en diferentes ambientes como epifitos, terrestres o saxicolas. El objetivo de este trabajo es dar a conocer los helechos y licofitas que habitan en el Parque Nacional Calilegua, con el fin de contribuir a la información sobre la biodiversidad en las Yungas y aportar a su conservación. El estudio se realizó teniendo en cuenta el material colectado en viajes de campo por diferentes zonas del Parque, durante los meses de diciembre a mayo de los años 2007 a 2011. Asimismo, se consultaron distintos herbarios nacionales y bibliografía específica. Se registraron en el PN Calilegua un total de 103 taxones (especies y variedades) de helechos y licofitas, agrupados en 18 familias y 43 géneros. Se dan a conocer seis nuevas citas para la provincia de Jujuy y se presentan actualizaciones nomenclaturales y claves para la identificación de los taxa registrados.

Palabras clave: Biodiversidad, helechos, licofitas, Parque Nacional Calilegua, Yungas.

${ }^{1}$ Cátedra de Botánica General, Facultad de Ciencias Agrarias, Universidad Nacional de Jujuy, Alberdi n 47, 4600 San Salvador de Jujuy, Argentina; aleganem@hotmail.com

${ }^{2}$ Facultad de Ciencias Naturales y Museo, Universidad Nacional de La Plata. Paseo del Bosque s/nº, 1900 La Plata, Argentina; gegiudice@hotmail.com

${ }^{3}$ Consejo Nacional de Investigaciones Científicas y Técnicas, Avda. Rivadavia 1917 - CP C1033AAJ - Ciudad Autónoma de Buenos Aires, Argentina; jpramosgiacosa@hotmail.com

${ }^{4}$ Comisión de Investigaciones Científicas de la Provincia de Buenos Aires, Camino Gral. Belgrano y 526, CP 1900, La Plata, Argentina; lujanluna@fcnym.unlp.edu.ar

${ }^{5}$ Orientación Plantas Vasculares, Depto. Cs. Naturales, FCEFQyNat, Universidad Nacional de Río Cuarto, Ruta 36 km 601, X5804ZAB, Río Cuarto, Córdoba, Argentina; marana@exa.unrc.edu.ar 


\section{INTRODUCCIÓN}

La Provincia Biogeográfica de las Yungas está ubicada sobre las laderas Orientales de los Andes, entre los 300 y los 3.500 m s.m. y recorre Sudamérica desde Venezuela hasta el Noroeste de la Argentina, en una franja angosta de $4000 \mathrm{~km}$ de extensión (Cabrera \& Willink, 1980; Morrone, 2001). Su clima es muy húmedo debido a las abundantes precipitaciones y a las neblinas, las cuales cubren casi continuamente las montañas. Por ese motivo la Provincia Biogeográfica de las Yungas también es denominada "nuboselva" y se la incluye dentro de los bosques nublados (Kapelle \& Brown, 2001).

Las Yungas poseen una importancia fundamental para la región por su gran diversidad biológica y por ubicarse como cabecera de cuenca de importantes ríos como el Bermejo, con su consecuente rol en la captación de aguas y regulación de los regímenes hídricos. Por esto, las Yungas han sido incluidas por la UNESCO dentro de las Reservas de la Biosfera del mundo. Uno de los objetivos de este sistema de protección es lograr un uso sustentable de los recursos existentes en ellas, para lo cual se prevé una zonificación del área según el estado de conservación y de uso requerido, logrando así zonas de protección total y zonas de uso sostenible.

Toda esta organización es aún muy incipiente en la "Reserva de las Yungas", por lo que se ha determinado que sólo los Parques Nacionales, Provinciales y Reservas que esta incluye constituyan las áreas de protección total o "core" de las mismas: Parque Nacional Baritú, Parque Nacional Calilegua, Parque Provincial Laguna Pintascayo, Parque Provincial Potrero de Yala y Reserva Natural Nogalar. La función de los "core" es mantener áreas lo más prístinas posibles para su estudio y su natural desarrollo, incluyendo los procesos sucesionales que puedan darse en el tipo de ecosistema protegido, el mantenimiento de riqueza genética, etc.

El conocimiento de las comunidades vegetales es fundamental para el posterior planteo de propuestas de uso sustentable de este ecosistema, así como para la comprensión de otras áreas similares.

La gran diversidad biológica de las Yungas, sumada a la variación altitudinal y latitudinal que presenta y a la dificultad de acceso y desplazamiento en la región, ha limitado el estudio de numerosos aspectos de su funcionamiento y de su composición florística.
El Parque Nacional Calilegua fue creado en 1979 y cuenta con 76.306 has que comprenden varios distritos o formaciones vegetales de la Provincia Fitogeográfica de las Yungas (Cabrera, 1976).

En este Parque los estudios florísticos comprenden en general aspectos taxonómicos (Cabrera, 1978; Ezcurra, 1994; Rivera, 1994; Johnson, 1998; Sanso \& Xifreda, 1995; Wulff et al., 1996; Xifreda, 1996; López et al., 1998) y en menor medida relevamientos de la vegetación (Muñoz et al., 1993; Morrone et al., 1999; Perovic et al., 2000; Rotman et al., 2007, 2008 a, 2008 b). Asimismo, existen varios informes internos de la Administración de Parques Nacionales que se hallan inéditos.

Cabe destacar que las condiciones ambientales de esta zona resultan óptimas para el desarrollo de una rica flora de helechos y licofitas, siendo ésta una de las áreas de mayor biodiversidad de la Argentina (Ponce et al., 2002).

El objetivo de este trabajo es dar a conocer los helechos y licofitas que habitan en el Parque Nacional Calilegua, con el fin de contribuir a la información sobre la biodiversidad en las Yungas y aportar a su conservación.

\section{Materiales y Métodos}

El estudio se realizó teniendo en cuenta el material colectado y/o identificado durante viajes de campo y la consulta de herbarios y bibiliografía específica. Se realizaron 5 viajes de campo entre diciembremayo de los años 2007-2011, recorriéndose distintas áreas del Parque (Fig. 1). El material colectado se halla depositado en el herbario de la Facultad de Agronomía de la UNJu (JUA), con duplicados en el herbario LP (Museo de Ciencias Naturales de La Plata) y en RCV (Dpto. Ciencias Naturales, Universidad Nacional de Río Cuarto).

Asimismo se consultaron los siguientes herbarios (Thiers, 2012): CORD, JUA, LIL, LP, MCNS, MERL, RCV y SI. En todos los casos se efectuó la determinación y actualización nomenclatural de los taxones en estudio.

Se cita en "Material representativo estudiado" un ejemplar por cada taxón y todos correspondientes a la provincia de Jujuy, Dpto. Ledesma, Parque Nacional Calilegua.

Para elaborar el listado de familias y géneros se consideró la propuesta de Christenhusz et al. (2011). 

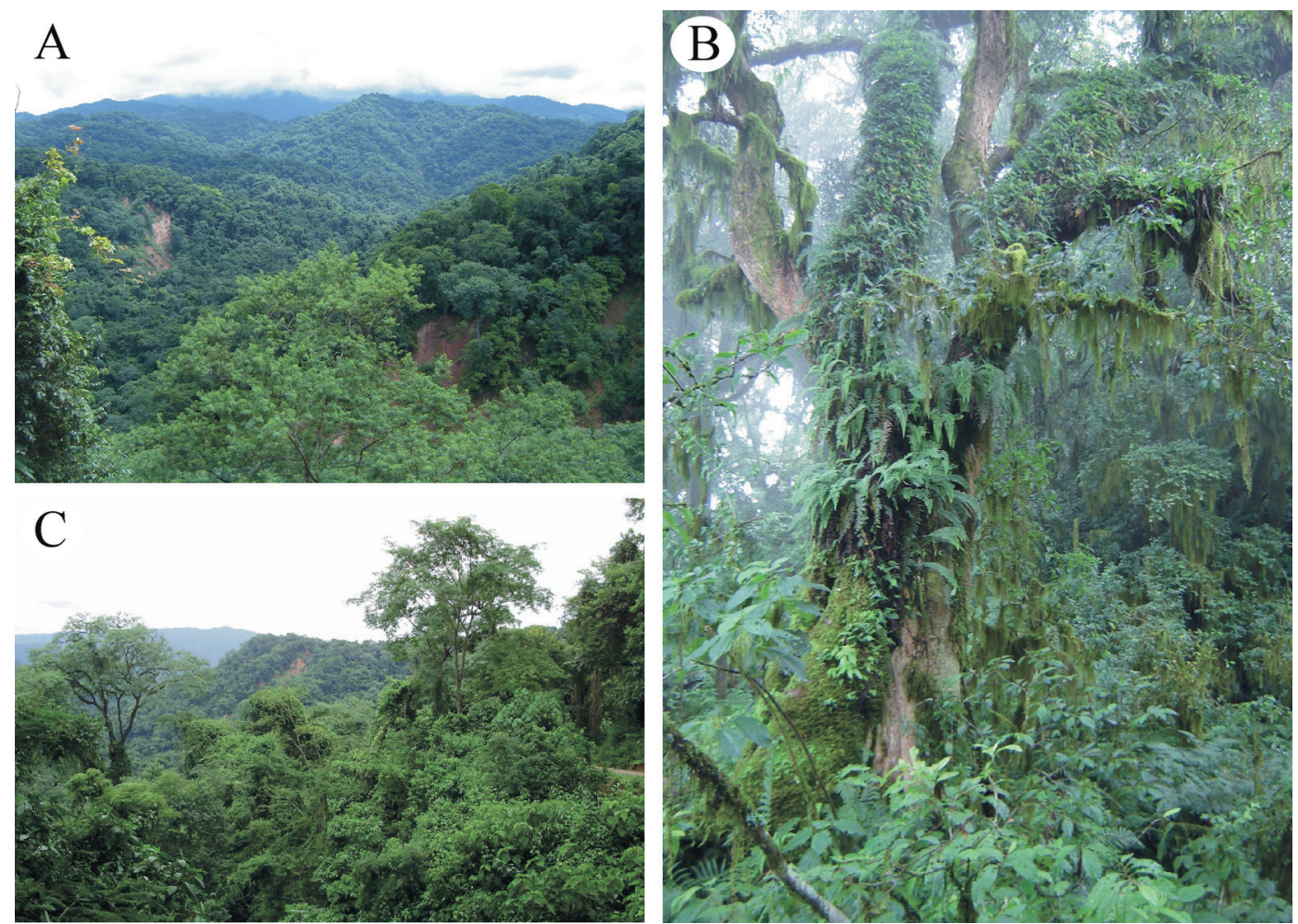

Fig. 1. Ambientes del Parque Nacional Calilegua.

\section{Resultados}

Se registraron en el PN Calilegua un total de 103 taxones (especies y variedades), de helechos y licofitas, agrupados en 18 familias y 43 géneros. Dentro de las licofitas las familias representadas son: Lycopodiaceae y Selaginellaceae, en tanto que en los helechos son: Anemiaceae, Aspleniaceae (Figs. 2 B, 3 C), Athyriaceae, Blechnaceae (Fig. 3 B), Cyatheaceae, Cystopteridaceae, Dennstaedtiaceae, Dryopteridaceae, Equisetaceae, Hymenophyllaceae (Figs. 3 A, 4 B, C), Ophioglossaceae, Polypodiaceae (Figs. 3 D, 4 A), Pteridaceae (Figs. 2 C, D), Salviniaceae, Thelypteridaceae y Woodsiaceae.
Se identificaron seis nuevos registros para la Provincia de Jujuy: Adiantum pseudotinctum, Asplenium claussenii (Fig. 2 B), Didymoglossum reptans, Diplazium cristatum, Pecluma venturii y Macrothelypteris torresiana. Asimismo se confirma la presencia de Asplenium cuspidatum y Phlegmariurus phylicifolius (Fig. 2 A) en Argentina y se registra por primera vez en el parque a Azolla filiculoides (Fig. 4 D).

Se presenta a continuación una clave para la determinación de los taxones de helechos y licofitas registrados en el PN Calilegua. En los casos de géneros con más de una especie se presentan luego las claves por género.

1. Plantas con expansiones laminares uninervias, licofilos. Esporangios sin anillo de dehiscencia, solitarios en cara adaxial del licofilo.

1'. Plantas con expansiones laminares plurinervias, eufilos. Esporangios con anillo de dehiscencia y ubicados en la cara abaxial de los eufilos o en láminas con hemidimorfismo o esporangios sin anillo y ubicados en estróbilos terminales o en soros cerrados o en esporóforos.

2. Plantas heterosporadas. Parte radical con rizóforos. Licofilos con lígula.

2'. Plantas homosporadas. Parte radical sin rizóforos. Licofilos sin lígula. 


\section{Bol. Soc. Argent. Bot. 48 (3-4) 2013}

3. Plantas con tallos isodicotómicos, sin ejes principales rastreros elongados; esporofilos fotosintéticos, persistentes luego de la dehiscencia del esporangio, ubicados en la parte apical del

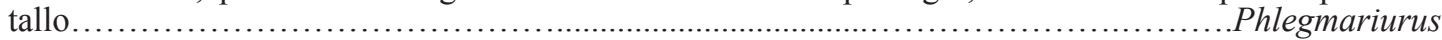

3'. Plantas con tallos anisodicotómicos, los principales rastreros y ejes secundarios laterales erectos; esporofilos diferenciados, caedizos luego de la dehiscencia del esporangio, reunidos en estróbilos diferenciados

4. Ejes erectos laterales con simetría dorsiventral, aplanados, trofofilos anisófilos, dispuestos verticiladamente...............................Diphasiastrum [D. thyoides (Humb. \& Bonpl. ex Willd.) Holub]

4'. Ejes erectos laterales con simetría radial, redondeados, trofofilos uniformes, dispuestos helicoidalmente Lycopodium [L. clavatum L. ssp. clavatum]

5. Ejes surcados y eufilos escuamiformes de disposición verticilada. Esporangios en estróbilos

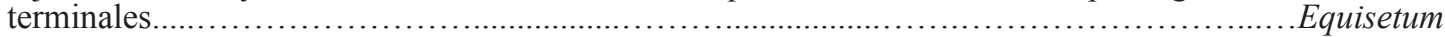

5'. Ejes no surcados, eufilos desarrollados de forma variada y de disposición helicoidal. Esporangios en soros u ocupando toda la superficie abaxial .....

6. Esporangios sin anillo de dehiscencia. Fronde con una parte estéril y una parte fértil (esporoforo). Vernación recta.......................................................... Botrychium [B. schaffneri Underw. vel aff.]

6'. Esporangios con anillo de dehiscencia. Vernación circinada.

7. Plantas heterosporadas, acuáticas. Azollla [A. filiculoides Lam.]

7'. Plantas homosporadas, terrestres o epifitas

8. Plantas delicadas, lámina 1-estratificada y sin estomas

8'. Plantas con láminas pluriestratificadas.

9. Indusio con dos valvas de margen entero o dentado y receptáculo incluso

9'. Indusio cónico y receptáculo exerto

Hymenophyllum

10. Plantas con raíces. Vandenboschia [V. angustata (Carmich.) Copel.]

10'. Plantas sin raíces Didymoglossum $[$ D. reptans (Sw.) C. Presl]

11. Ejes caulinares arborescentes mayores a $1 \mathrm{mt}$.de altura Alsophila [A. odonelliana Alston (Lehnert)]

11 '. Ejes caulinares de porte arborescente menores de $1 \mathrm{mt}$ de altura o no arborescentes

12. Láminas hemidimórficas, con 2 pinnas basales fértiles y el resto estériles y esporangios con anillo apical

2'. Láminas isomórficas y esporangios con anillo oblicuo o vertical Anemia

13. Rizomas largamente rastreros, pilosos y base del pecíolo también con pelos. Láminas 3-4-pinnadas.(14)

13'. Rizomas erectos, oblicuos o rastreros, escamosos, y base de los pecíolos con escamas y (o) pelos, o glabros. Láminas enteras, 1-2-pinnado-pinnatífidas, raro 3-pinnadas (Megalastrum)..

14. Soros protegidos por indusio. Esporas triletes..............Dennstaedtia [D. globulifera (Poir.) Hieron.] 14 '. Soros protegidos por margen reflexo de la lámina. Esporas monoletes.

.Hypolepis [Hypolepis poeppigii (Kunze) R. Rodr.]

15. Esporangios agrupados en soros marginales o a lo largo de las venillas o entre venas, protegidos por pseudoindusios (margen reflexo de la lámina).

$15^{\prime}$. Esporangios agrupados en soros o dispuestos superficialmente, con o sin indusio, nunca marginales ....

16. Esporangios a lo largo de las venas laterales, a veces confluentes a la madurez

16 '. Esporangios en el extremo de las venillas o a lo largo de una vena colectora marginal, protegidos o no por el margen reflexo de la lámina...

17. Plantas con frondes arrosetadas y dimórficas, laminas estériles enteras, las fértiles largamente pecioladas, pinnatifidas a pinnadas. .Trachypteris [T. pinnata (Hook.f.) C. Chr.]

17". Plantas con frondes no arrosetadas e isomorficas. Laminas divididas.....

18. Plantas delicadas de hasta $5 \mathrm{~cm}$.y glabras. Anogramma $[$ A. lorentzii (Hieron.) Diels]

18'. Plantas más robustas mayores a $5 \mathrm{~cm}$, láminas 1-pinnadas, cerosas o pilosas.

19. Láminas pilosas, con pinnas enteras. Hemionitis [H. tomentosa (Lam.) Raddi] 
19'. Láminas con ceras amarillas, con pinnas enteras, bi y trifolioladas. Trismeria [T. trifoliata (L.) Diels]

20. Esporangios ubicados sobre el margen reflexo de la lámina.

Adiantum

20'. Esporangios protegidos o no por el margen reflexo de la lámina, pero nunca ubicados sobre éste......(21)

21. Esporangios sobre vena colectora marginal protegidos por el margen reflexo.

Pteris

21 '. Esporangios en el extremo de venillas, distribuidos en toda la lámina o conformando soros o cenosoros, protegidos o no por el margen reflexo.

22. Laminas palmatipartidas

Doryopteris

22'. Láminas pinnadas.

23. Pecíolos y ejes surcados, con estrechas alas laterales. Láminas 2-3-pinnado- pinnatífidas, glabras Adiantopsis [A. chlorophylla (Sw.) Fée]

23'. Pecíolos teretes o semiteretes. Láminas usualmente menos divididas, escamosas, cerosas.

24. Láminas coriáceas, con ceras Soros protegidos por el margen reflexo no modificado........Argyrochosma

24'. Láminas pilosas o glabras. Soros protegidos por el márgen reflexo interrumpido y modificado ............................................................................. pheilanthes [Ch. poeppigiana Mett. Ex Kuhn]

25. Láminas pinnatífidas, pinnatisectas o enteras, glabras, pilosas o escamosas Esporangios agrupados en soros desnudos.

25'. Láminas pinnadas a 4-pinnadas, si enteras con esporangios cubriendo toda la superficie abaxial.....

26. Láminas enteras, ocasionalmente pinnatilobadas.

26'.Láminas pinnatifidas o pinnatisectas.

27. Laminas escamosas abaxialmente y con escasas escamas en la adaxial, soros elípticos con parafisos escuamiformes peltados. Pleopeltis

27'. Láminas glabras, con escamas caducas en la costa, soros con parafisos filamentosos o sin ellos.

28. Frondes dimorfas. Soros uniseriados, parafisos filamentosos y ramificados. ..Microgramma [M. squamulosa (Kaulf.) de la Sota]

28 '. Frondes isomorfas. Soros 1-2 seriados, sin parafisos Campyloneurum

29. Láminas glabras. Phlebodium [Ph. aureum (L.) J.Sm.]

29'. Láminas escamosas o pilosas.

30. Rizomas con escamas clatradas, peltadas. Láminas con escamas en cara abaxial... Serpocaulon [S. gilliesii (C.Chr.) A.R. Sm.]

30'. Rizomas con escamas no clatradas .Láminas pilosas. Pecluma

31. Esporangios agrupados en soros paralelos a las costas, con indusio lateral que se abre hacia el centro de la pinna...... Blechnum

31'. Esporangios cubriendo la superficie abaxial de la lámina o agrupados en soros circulares o linearelípticos, indusios de otras formas o ausentes.

32. Esporangios cubriendo toda la superficie abaxial de la lámina o agrupados en soros circulares, con indusios orbiculares o reniformes, o desnudos.

32 '. Soros lineales, con indusio fijo lateralmente, o soros circulares, con indusio fijo dorsal o basalmente, a menudo inconspicuos.

33. Esporangios cubriendo toda la superficie abaxial de la lámina. Lámina entera o pinnada.....

33'.Esporangios en soros. Lámina pinnado- pinnatifida a tri- pinnada.

34. Lámina entera con venación libre.

Elaphoglossum

34'. Lámina pinnada con venación reticulada....................Bolbitis [B. serratifolia (Mert. Ex Kaulf.) Schott]

35. Soros con indusio peltado. Ejes y segmentos menores (cara abaxial) con escamas filiformes .Polystichum

35 '. Soros con indusio reniforme o ausente. Ejes y segmentos menores con pelos o glabros.

36. Indusio ausente. Ejes con pelos blanquecinos, aciculares Megalastrum

36'.Indusios reniformes. Ejes con pelos de otro tipo. 
37. Raquis y costa con pelos rojizos pluricelulares.....Ctenitis [C. submarginalis (Langsd. \& Fisch.) Ching]

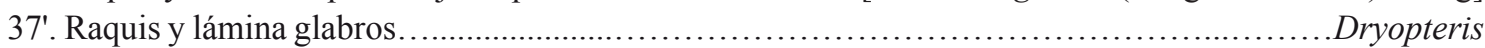

38. Escamas rizomáticas clatradas. Soros lineales con indusios laterales...................................Asplenium

$38^{\prime}$. Escamas rizomáticas no clatradas. Soros circulares o elípticos, con indusios dorsales, basales o basi-laterales.

39. Láminas con pelos simples, 1-celulares, aciculares o setiformes, a menudo con glándulas rojizas. Soros circulares, con indusio piloso o glanduloso-piloso, inconspicuo, a menudo reducido a un fascículo de pelos.

39'. Láminas glabras, o con pelos simples o glandulares, pluricelulares. Soros circulares o elongados, con indusio basal o basi-lateral, glabro o piloso, notorio

40. Láminas bi a tripinnado pinnatifidas. Venas ensanchadas en el ápice que no alcanzan el margen..... (Gaudich) Ching]

40'. Láminas pinnadas a pinnadas pinnatífidas. Venas no ensanchadas en el ápice, alcanzando el margen. Thelypteris

41. Láminas de hasta 2 mts. Soros elongados con indusios de inserción lateral.

Diplazium

41'. Láminas menores. Soros circulares con indusios basifijos o ínferos.

42. Plantas glabras o con escasos pelos glandulares Láminas bi-tripinnadas. Soros cubiertos por indusios basifijos, cupuliformes, glabros o con pelos glandulares...........Cystopteris [C. diaphana (Bory) Blasdell]

42'. Plantas glanduloso- pilosas. Láminas pinnadas o bipinnadas. Soros con indusios ínferos en forma de platillo con pelos glandulares. .Woodsia [W. montevidensis (Spreng.) Hieron.]

\section{Adiantum L.}

\section{Claves de especies}

1. Pinnulas dimidiadas, con vena submarginal basiscópica evidente, pseudoindusios ubicados acroscópicamente. Adiantum pectinatum Desv.

1'. Pinnulas flabeladas o palmadas, venación dicotómica una o varias veces furcadas, sin vena submarginal evidente.

2. Pinnulas palmadas. Rizomas con porción estoloniforme. Raquis en zig-zag. Pseuodindusios cuadrangulares o rectangulares. Adiantum digitatum Hook.

2'. Pinnulas flabeladas. Rizomas corta a largamente rastreros. Raquis rectos a algo sinuosos.

3. Pseudoindusios reniformes a rectangulares. Escamas rizomaticas ciliadas.........Adiantum poiretii Wikstr.

3'. Pseudoindusios orbiculares. Escamas rizomaticas enteras.

4. Rizoma largamente rastrero

4'. Rizoma cortamente rastero. Adiantum pseudotinctum Hieron.

5. Pinnulas con relación largo/ancho 2:1 con base cuneado.-asimétrica. Peciólulos menores de $2 \mathrm{~mm}$......... Adiantum raddianum $\mathrm{C}$. Presl

5'. Pinnulas con relación largo/ancho 1:2 con base cuneado- simétrica. Peciólulos mayores de $2 \mathrm{~mm} . . . . .$.

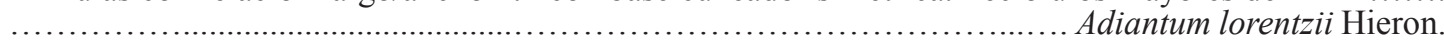

\section{Anemia Sw.}

1. Láminas bipinnadas a bipinnado-pinnatífida. Anemia australis (Mickel) M. Kessler \& A.R Smith

1 '. Láminas pinnadas, con nerviación anastomosada o libre.

2. Pinnas con base simétrica, costa bien marcada, anastomosis frecuentes y regulares entre las venas laterales...... Anemia phyllitidis (L.) Sw.var. phyllitidis

2'. Pinnas con base asimétrica, costa en general poco marcada, anastomosis poco frecuentes a ocasionales entre las venas laterales. Anemia herzogii Rosenst.

\section{Argyrochosma (J. Sm.) Windham}

2. Láminas tripinnadas, con cera amarilla....Argyrochosma nivea (Poir.) Windham var. flava (Hook.) Ponce

2'. Láminas en general bipinnadas, glabras. .Argyrochosma nivea (Poir.) Windham var. tenera (Gillies ex Hook.) Ponce 


\section{Asplenium L.}

1. Frondes con láminas bipinnadas.

1'. Frondes con láminas nunca bipinnadas.

2. Plantas terrestres, láminas de consistencia herbácea. Pinnas de base cuneado asimétrica, sin lóbulo basal acroscópico.

Asplenium squamosum L.

2'. Plantas epifíticas, láminas coriáceas. Pinnas proximales con un lóbulo basal acroscópico Asplenium cuspidatum Lam.

3'. Láminas 1-pinnadas, con pinnas no auriculadas en la base Asplenium auritum $\mathrm{Sw}$.

4. Pecíolos purpúreos a negros lustrosos. Pinnas con un solo soro, rarísimo dos en el lado basiscópico. Asplenium monanthes L.

4'. Pecíolos verdosos a castaños oscuros, nunca negros lustrosos. Con varios soros por pinna.

5. Plantas con largos ejes gemíferos y radicantes en sus extremos. Asplenium lorentzi Hieron.

5'. Plantas sin ejes gemíferos radicantes en sus extremos.

6. Soros en ángulo agudo con la costa, hasta subparalelos a ella. Asplenium serra Langsd. \& Fisch.

6'. Soros nunca en ángulo agudo con la costa.

7. Pinnas proximales descendentes, auriculadas acroscópicamente, de ápice obtuso y margen crenado. Pinnas basales gradualmente reducidas. Asplenium claussenii Hieron.

7'. Pinnas proximales perpendiculares o ascendentes.

8. Pinnas perpendiculares a subascendentes, elípticas-falcadas, agudas, lineales. Margen basicóspico entero y margen acroscópico dentado-serrados, ápices subatenuados-redondeados. Pinnas basales reducidas Asplenium argentinum Hieron.

8'. Pinnas ascendentes, perpendiculares al raquis, fuertemente inequilaterales. Margen crenado a profundamente 2-serrado. pinnas basales poco reducidas o un par basal apenas menor..........................................................................................Asplenium inaequilaterale Willd.

Obs.: De acuerdo a lo analizado en el presente estudio la mayor parte del material de Argentina determinado hasta el momento como Asplenium auritum es Asplenium cuspidatum. Estas se pueden diferenciar por la división de la lamina, en $A$. auritum es pinnada-pinnatifida y A. cuspidatum es bipinnada a mas dividida.

\section{Blechnum L.}

1. Frondes monomórficas o subdimórficas, cenosoros de posición costal a media

1'. Frondes dimórficas, cenosoros de posición marginal.

2. Pinnas membranáceo-herbáceas, con márgenes ciliados. Ejes, láminas e indusios glandular pubescentes. Blechnum laevigatum Cav.

2'. Pinnas subcoriáceas, con márgenes no ciliados. Ejes, láminas e indusios glabros.

Blechnum occidentale L. var. occidentale

3. Rizoma arborescente.

3'. Rizoma no arborescente.

4. Pinnas con margen entero. Escamas del rizoma y de la base del pecíolo aciculares

Blechnum yungense Ramos Giacosa

4'. Pinnas con margen aserrado. Escamas del rizoma y de la base del pecíolo anchas.

Blechnum cordatum (Desv.) Hieron

5. Frondes con raquis gemífero. Pinnas con base contraída. Blechnum sprucei C. Chr.

5 '. Frondes sin raquis gemífero. Pinnas con base adnata. Blechnum squamipes (Hieron.) M. Kessler \& A.R. Sm.

\section{Campyloneurum C. Presl}

1. Láminas lineales, $1 \mathrm{~cm}$ de ancho aproximadamente, rizomas delgados con escamas brillantes. Una o dos hileras de soros. Campyloneurum aglaolepis (Alston) de la Sota 
1'. Láminas lanceoladas, anchas (más de $1 \mathrm{~cm}$ ). Rizomas robustos con escamas opacas. Soros multiseriados.

2. Láminas grandes y anchas, hasta $12 \mathrm{~cm}$ lat, membranáceo herbáceas, nerviación compleja, visible.

Campyloneurum tucumanense (Hieron.) Ching

2'. Láminas menores, mas angostas, consistencia más rígida, nerviación sencilla, poco visible.

Campyloneurum nitidum C. Presl

\section{Diplazium Sw.}

1. Láminas de contorno triangular, tripinnado a tripinnado- pinnatífidas. Ultimos segmentos adnatos, ascendentes, glabros, dentados. Venas 1-2 furcadas. Soros algo alargados, ubicados entre costa y margen

Diplazium lilloi (Hicken) R.M. Tryon \& A.F. Tryon

1'. Láminas de contorno elíptico-lanceolado, pinnado-pinnatífidas. Ultimos segmentos de margen entero o con escasos dientes distantes. Venas simples. Soros alargados, ubicados en parte media de una venilla fértil. Soros dobles en la primer venilla, soros restantes simples acroscópicos. Diplazium cristatum (Desr.) Alston

\section{Doryopteris J. Sm.}

1. Láminas con venación completamente abierta. D. concolor (Langsd. \& Fisch.) Kuhn

1'. Láminas con venación parcial o totalmente areolada.

2. Láminas grandes, con yemas prolíferas en la base, pecíolos claros y robustos

Doryopteris majestosa J. C. Yesilyurt

2'. Láminas pequeñas a medianas, sin yemas prolíferas, pecíolos oscuros y delgados. Doryopteris pentagona Pic. Serm.

Obs.: De acuerdo a los estudios realizados por Yesilyurt (2007) Doryopteris nobilis no crece en Argentina. Lo que ha sido determinado como tal es $D$. majestosa. D. nobilis no tiene yemas en la base de su lámina, hipofilo con escasos pelos a glabro y peciolo surcado, en tanto que $D$. majestosa tiene yemas en la base de la lámina, pecíolos teretes y la base y zonas medias de lámina pubescentes.

De esta manera, lo citado e ilustrado como D. nobilis por de la Sota (1977: 93, 96, fig.36) es D. majestosa, excluyéndose de Argentina la especie Doryopteris nobilis, que habita el sureste de Brasil.

\section{Dryopteris Adans.}

1. Láminas de contorno elíptico-lanceolado, pinnado-pinnatífidas, con ejes densamente escamosos, plantas terrestres.

Dryopteris wallichiana (Spreng.) Hyl.

1'. Láminas de contorno deltoide a aovado-deltoide, más divididas, glabrescentes, plantas epífitas o terrestres. Dryopteris patula (Sw.) Underw.

Elaphoglossum Schott ex J. Sm.

1. Láminas coriáceas, glabras o con pequeños tricomas o escamas caducas.

1'. Láminas escamosas o pilosas

2. Láminas glabras con margenes revolutos

Elaphoglossum gayanum (Fée) T. Moore

2'. Láminas con ambas superficies de la lámina con diminutos tricomas estrellados o aracniformes, castañorojizos, costa abaxial con escamas remotísimas, castaño oscuras de base ancha.

Elaphoglossum sellowianum (Klotzsch ex Kuhn) T. Moore

3. Plantas fértiles con láminas pequeñas de hasta $20 \mathrm{~cm}$.

3'. Plantas fértiles con láminas mayores, plantas robustas, rizomas gruesos.

4. Rizomas largamente rastreros, frondes distancias, las fértiles elíptico- lanceoladas, planas; las esteriles con envés glabro. Elaphoglossum lorentzii (Hieron.) H. Christ.

4'. Rizomas cortamente rastreros, frondes aproximadas, las fertiles anchas, elipticas a orbiculares, las estériles con ambas caras escamosas. Elaphoglossum piloselloides (C.Presl) T. Moore

5. Láminas con pelos ramificados y pelos glandulares en hipofilo, epifilo con escamas estrellada a glabrescentes. Elaphoglossum yungense de la Sota

5'.Láminas escamosas 
6. Laminas con ambas caras escamosas, el hipofilo en mayor densidad.

Elaphoglossum crassipes (Hieron.) Diels

6'. Laminas con escamas oscuras sobre la costa y margenes, el resto glabro......

Elaphoglossum lindbergii (Mett. Ex Kuhn) Rosenst.

Equisetum Michx. Ex DC.

1. Plantas de hasta $40 \mathrm{~cm}$. de altura, con numerosos tallos macizos, simples a escasamente ramificados. .Equisetum bogotense Kunth

1'. Plantas mayores a 1 de altura, con tallos huecos, fistulosos y muy ramificados.

Equisetum giganteum L.

\section{Hymenophyllum Sm.}

1. Láminas glabras, ocasionalmente con pelos simples sobre el raquis y las nervaduras

1'. Láminas con pelos bifurcados o estrellados sobre las nervaduras y los márgenes

2. Segmentos de las pinnas con márgenes dentados

............................................................Hymenophyllum tunbridgense (L.) Sm. var. cordobense Hieron

2' Segmentos de las pinnas con márgenes enteros.

3. Láminas ondulado-crispadas Hymenophyllum polyanthos (Sw.) Sw.

3'. Láminas planas. Hymenophyllum crispum Kunth

Megalastrum Holtum

1. Soros submarginales, cara abaxial de la lamina con pelos cortos densos, cara adaxial con pelos largos esparcidos. Megalastrum adenopteris (C. Chr.) A. R. Sm \& R. C. Moran

1'. Soros entre la costa y margen. Cara abaxial y adaxial de la lámina con pelos largos blanquecinos. Megalastrum pulverulentum (Poir.) A.R. Sm \& R. C. Moran

Pecluma M. G. Price

1. Frondes menores a $20 \mathrm{~cm}$. Raquis pilosos-escamosos .Pecluma filicula (Kaulf.) M. G. Price

1 '. Frondes mayores a $20 \mathrm{~cm}$. Raquis pilosos, nunca escamosos.

2. Pinnas cortas anchas, de ápice redondeado, pilosas. ..Pecluma venturii (de la Sota) M.G. Price

2'. Pinnas largas angostas, ápice atenuado, glabrescentes. Pecluma oranense (de la Sota) de la Sota

\section{Phlegmariurus (Herter) Holub}

1. Plantas con esporofilos muy diferentes a los trofofilos, mucho más reducidos y ubicados en el ápice de los tallos. .Phlegmariurus phylicifolius (Desv. ex Poir.) B. Øllg.

1'. Plantas con los esporofilos similares a los trofofilos, sin diferenciarse claramente entre ellos................2

2. Plantas epifíticas, con tallos péndulos a erecto. Phlegmariurus sotae (Rolleri) B. Øllg.

2'. Plantas terrestres, con tallos erectos columniformes simples o bifurcados. .3

3. Trofofilos reflexos, patentes a recurvados, con margen denticulado a ciliado.

Phlegmariurus reflexus (Lam.) B. Øllg.

3'. Trofofilos no reflexos, adpresos al tallo o patentes, con margen entero a denticulado.

Phlegmariurus saururus (Lam.) B. Øllg.

Obs: Øllgard (1992) considera a Phlegmariurus phylicifolius como probable en Argentina, sin citar material de referencia. En el presente estudio se confirma esta especie para Argentina, ya que todo el material citado previamente como Phlegmariurus subulatus corresponde a Lycopodium nubigenum Herzog, un sinónimo de Phlegmariurus phylicifolius. 


\section{Bol. Soc. Argent. Bot. 48 (3-4) 2013}

Pleopeltis Humb. \& Bonpl. Ex Willd.

1. Láminas enteras. Pleopeltis macrocarpa (Bory ex Willd.) Kaulf.

1'. Laminas pinnatisectas a pinnadas.

2. Laminas pinnatisectas. Pleopeltis tweediana (Hook.) A.R. Sm.

2'. Laminas pinnadas

3. Envés densamente cubierto por escamas ovadas, cubriendo totalmente la superficie abaxial; nerviación con venillas laterales libres, furcadas hasta anastomosadas, determinando una serie de areolas a ambos lados de la costa, con una venilla inclusa. Pleopeltis minima (Bory) J. Prado \& R. Y. Hirai

3 '. Envés con pequeñas escamas esparcidas. Venas laterales poco visible s 1-2 veces surcadas, libres

Pleopeltis pleopeltidis (Fée) de la Sota

\section{Polystichum Roth}

1. Láminas con raquis gemíferos cerca del ápice, pínnulas de 13 a 18 pares por pinna, de hasta $20 \mathrm{~mm} \mathrm{x}$ $10 \mathrm{~mm}$ Polystichum platyphyllum (Willd.) C. Presl var. platyphyllum

2. Láminas con raquis no gemíferos, pínnulas de 15 a 25 pares por pinna, de hasta $12 \times 6 \mathrm{~mm}$. Polystichum montevidense (Spreng.) Rosenst.var. montevidense

\section{Pteris}

1. Frondes con láminas, pinnadas o a lo sumo con las pinnas basales nuevamente divididas

1'. Frondes con láminas varias veces pinnadas.

2. Venación libre Pteris cretica $\mathrm{L}$.

$2^{\prime}$. Venación reticulada. Pteris denticulata Sw.var. denticulata

3. Pinnas basales similares en longitud a las siguientes, con el ápice largamente caudado. Escamas rizomáticas no ciliadas.

Pteris plumula Desv.

3'. Pinas basales mucho mayores en longitud a las siguientes, con el ápice no caudado. Escamas rizomáticas ciliadas.

4. Láminas con raquis, costa y cóstulas con procesos espinosos blanquecinos.

Pteris inermis (Rosenst.) de la Sota

4'. Láminas con raquis, costa y cóstulas sin procesos espinosos.

5. Márgenes de los segmentos estériles conspicuamente dentados. Indusios de 0,5-5 mm long. Pteris exigua O.G.Martínez \& J.Prado

5'. Márgenes de los segmentos estériles enteros o muy cortamente dentados. Indusio de 5-12 mm long. ...... .Pteris deflexa Link.

\section{Selaginella P. Beauv.}

1. Trofofilos monomórficos, dispuestos helicoidalmente. Selaginella sellowii Hieron.

1'. Trofofilos dimórficos, dispuestos en cuatro hileras

2. Tallos postrados, con rizóforos presentes en todo su largo Selaginella microphylla (Kunth) Spring

2'.Tallos suberectos, con rizóforos sólo en su parte basal. Selaginella novae-hollandiae (Sw.) Spring

\section{Thelypteris Schmidel}

1. Pinnas basales no reducidas o los primeros 2-3 pares levemente reducidos....

1'. Numerosos pares de pinnas basales gradualmente reducidas (en general más de 4) los últimos pares con pinnas pequeñas, hastadas o auriculadas.

2. Venas basales de los segmentos adyacentes anastomosadas formando una venilla excurrente al seno....(3)

2'. Venas basales libres, conniventes o no en el seno, si anastomosadas no forman vena excurrente.

3. Rizomas desnudos; frondes remotas sobre el rizoma; pinnas incisas hasta la mitad de la distancia a la costa; con escamas ovadas en la costa abaxial. Thelypteris interrupta (Willd.) K. Iwats

3'. Rizomas erectos o rastreros, escamosos por lo menos en elápice; frondes fasciculadas sobre el rizoma; pinnas 
incisas hasta $2 / 3$ o más de la distancia a la costa, escamas ausentes.

Thelypteris hispidula (Decne) C.F.Reed

4. Segmentos basales acrosocópicos de las pinnas elongados, de mayor tamaño que los siguientes; ápice de lámina gradualmente reducido.

4'. Primeros pares de segmentos de las pinnas muy reducidos u obsoletos; ápice de lámina abruptamente reducido. Thelypteris grandis A.R. Sm. var. kunzeana (Hook.) A.R. Sm.

5. Cóstulas y venas glabras adaxialmente; escamas rizomáticas glabras.

Thelypteris patens (Sw.) Small var. patens

5'. Cóstulas y venas pilosas o esparcidamente pilosas. Escamas rizomáticas pilosas.

6. Raquis con pelos fasciculados

Thelypteris patens (Sw.) Small var. smithiana Ponce

6'. Raquis glabro o con pelos no fasciculados.

Thelypteris achalensis (Hieron.)Abbiatti

7. Cápsula de los esporangios con setas.

7'. Cápsula de los esporangios glabra, sin setas.

8. Soros con indusio reniforme.

Thelypteris concinna (Willd.) Ching

8'. Soros desnudos, sin indusio.

Thelypteris jujuyensis de la Sota .Thelypteris nubicola de la Sota
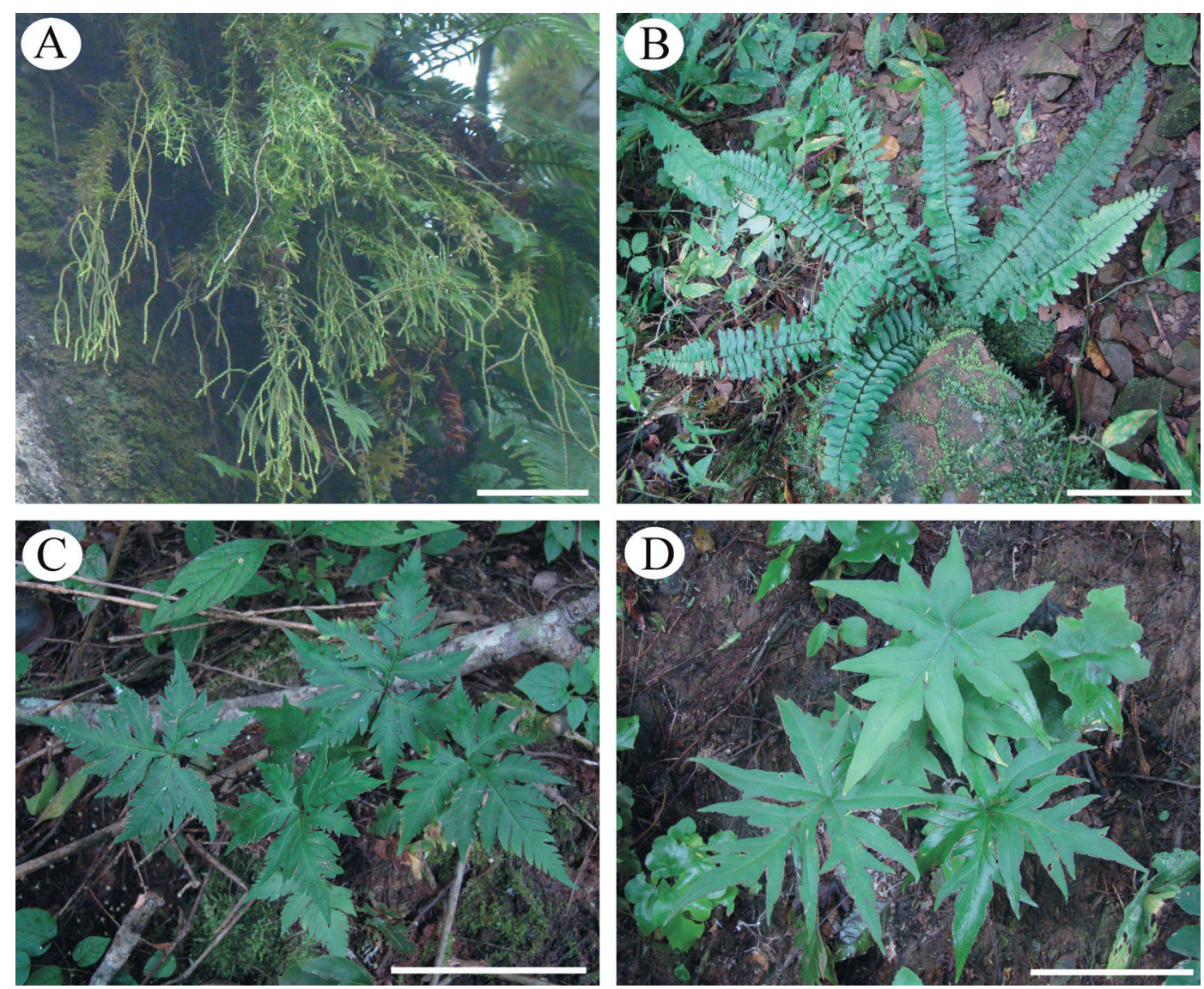

Fig. 2. Licofitas y helechos del Parque Nacional Calilegua. A: Phlegmariurus phylicifolius. B: Asplenium claussenii. C: Doryopteris concolor. D: Doryopteris pentagona. Escalas: A-D: $10 \mathrm{~cm}$. 

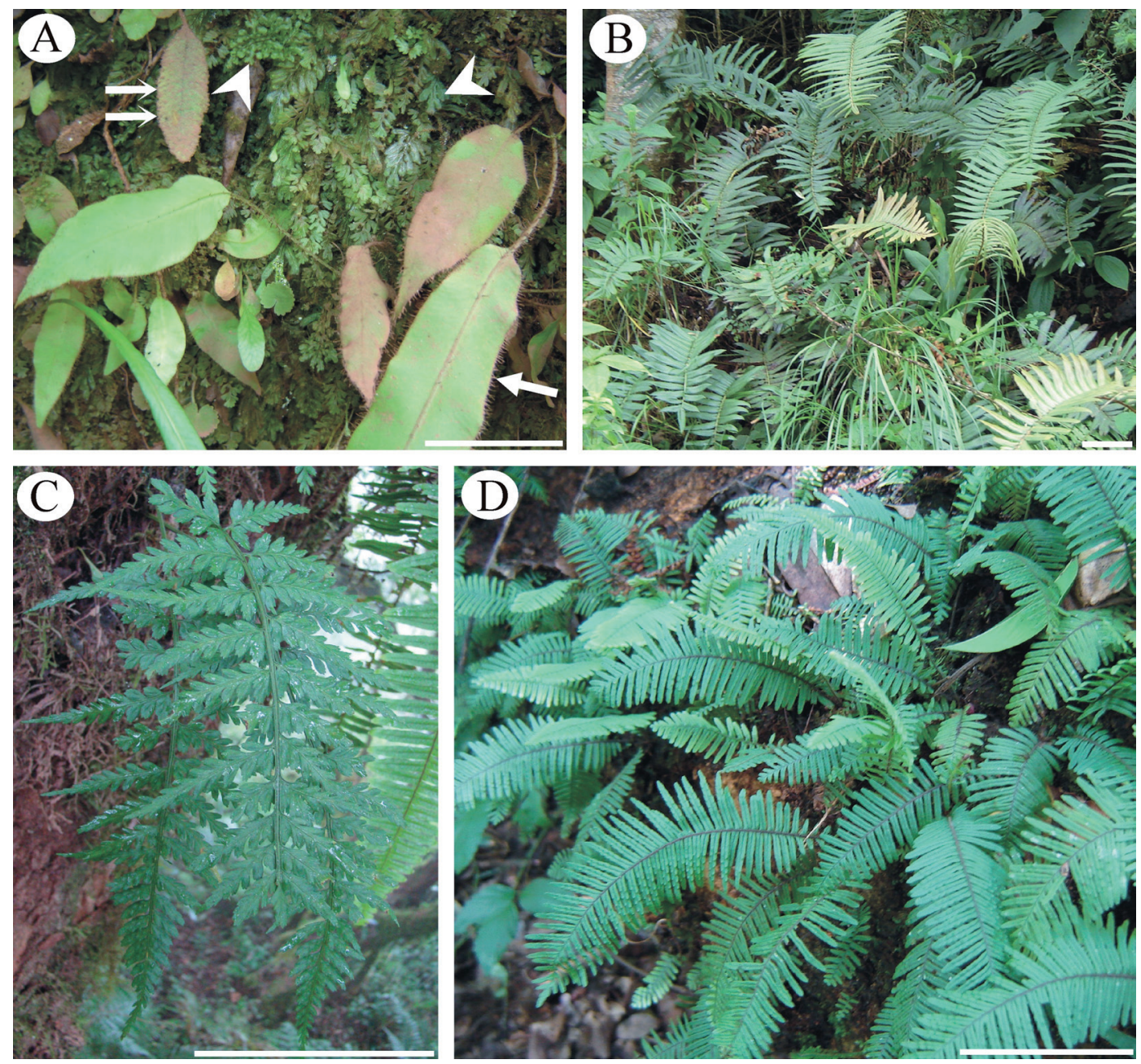

Fig. 3. Helechos del Parque Nacional Calilegua. A: Elaphoglossum lindbergii (flecha) y E. piloselloides (doble flecha) creciendo con diversas especies de Hymenophyllum (puntas de flechas) B: Blechnum yungense. C: Asplenium cuspidatum. D: Pecluma filicula. Escalas: A: $5 \mathrm{~cm}$. B-D: $10 \mathrm{~cm}$.

\section{Material REpresentativo ESTUDIADO}

\section{ANEMIACEAE}

Anemia australis: Descendiendo desde Monolito hacia Mesada de las Colmenas, $23^{\circ} 40^{\prime} 58^{\prime \prime} \mathrm{S} 64^{\circ}$ 54'04” W, 1720 m.s.m, 04/07/2010, Larsen 134 \& Arana (SI, RCV). Anemia herzogii: Sendero Tataupá, 2/2009, Ramos Giacosa et al. 36 (JUA, LP). Anemia phyllitidis var. phyllitidis: Mesada de las Colmenas, sendero de la Cascada, $1100 \mathrm{msm}$, 12/11/2002, Ramos Giacosa 117 (LP).
ASPLENIACEAE

Asplenium argentinum: Sendero Tataupá, 2/2009, Ramos Giacosa et al. 49 (JUA, LP). Asplenium auritum: Sendero que une el camino principal con Arroyo El Negrito (Sendero 4) $23^{\circ} 44^{\prime}$ 20" S 64 51' 14" W, 758 m.s.m., 4/7/2010, Larsen 130\& Arana (SI, RCV). Asplenium claussenii: Zona pozos de petróleo yacimiento El Caimancito, 23/5/2011, Ganem et al. 17 (JUA, LP, RCV). Asplenium cuspidatum: Camino a Mesada de las Colmenas, 24/5/2011, Ganem et al 29 (JUA, LP, $\mathrm{RCV})$. Asplenium inaequilaterale: Camino de 

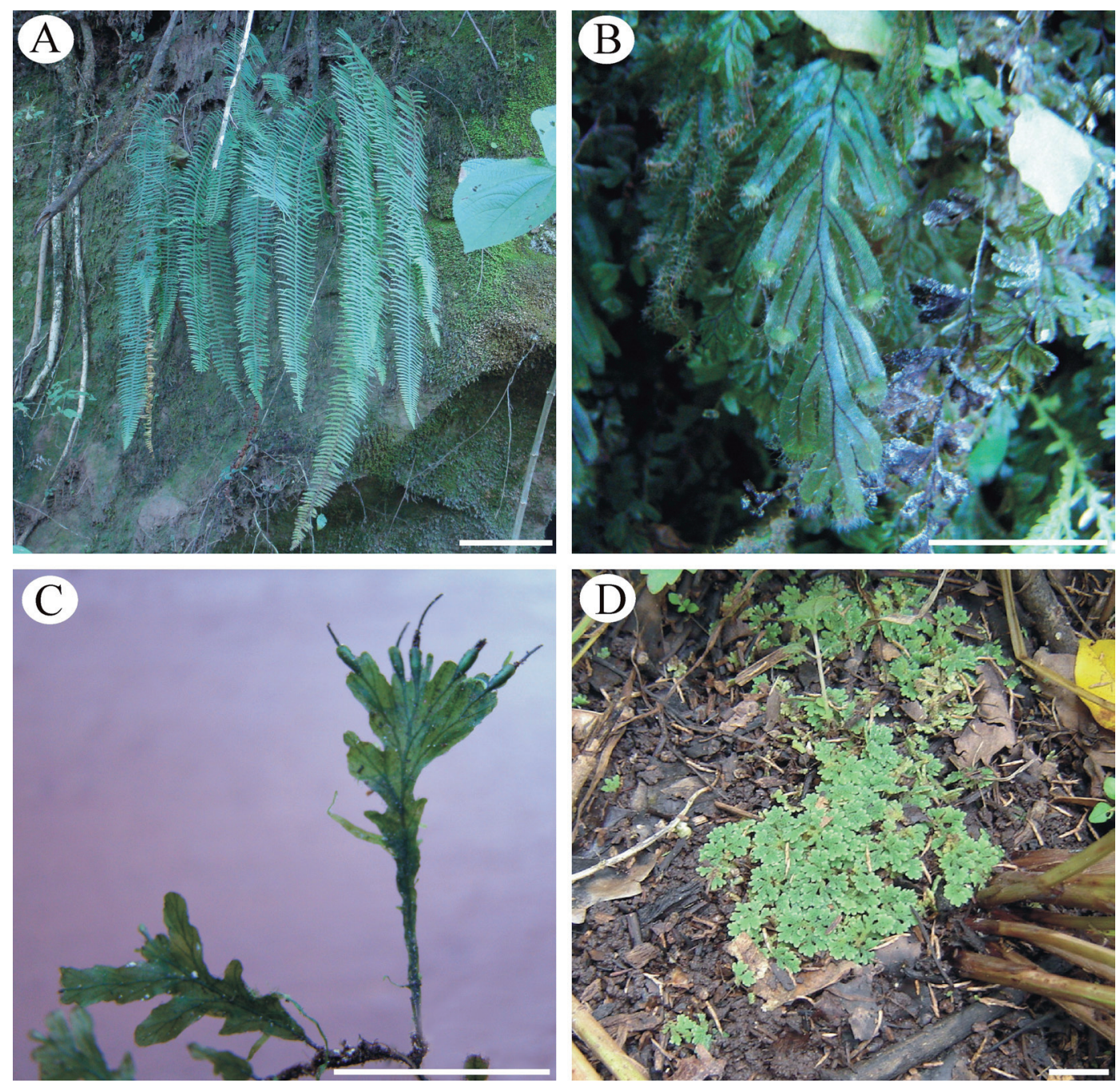

Fig. 4. Helechos del Parque Nacional Calilegua. A: Plecluma oranense. B: Hymenophyllum capurroi. C: Didymoglossum reptans. D: Azolla filiculoides. Escalas: A: $10 \mathrm{~cm}$. B-D: $3 \mathrm{~cm}$.

Abra de las Cañas a Mesada de las Colmenas, $23^{\circ}$ 41' S $64^{\circ} 54^{\prime} \mathrm{W}, 1650$ m.s.m, 12/11/2002, Ramos Giacosa et al. 125 (LP). Asplenium lorentzii: Camino a Mesada de las Colmenas, 24/5/2011, Ganem et al 32 (JUA, LP, RCV). Asplenium monanthes: Serranía de Calilegua, Tolditos, Fabris, Crisci \& Petriella 5933 (LP). Asplenium serra: Aguada de Tigre, $23^{\circ} 41^{\prime} 03^{\prime \prime} \mathrm{S} 64^{\circ} 53^{\prime} 40^{\prime \prime} \mathrm{W}, 1630$ m.s.m. 05/07/10, Larsen 155 \& Arana (SI, RCV). Asplenium squamosum: Camino a Mesada de las Colmenas, 24/5/2011, Ganem et al 31 (JUA, LP, RCV).

\section{ATHYRIACEAE}

Diplazium cristatum: Calilegua, 30/09/1994, Ahumada 7158 (JUA). Diplazium lilloi: camino a Mesada de las Colmenas, 24/5/2011, Ganem et al 28 (JUA, LP, RCV).

\section{BLECHNACEAE}

Blechnum cordatum: Camino hacia Abra de las Cañas, 2/2009, Ramos Giacosa et al. 45 (JUA, LP). Blechnum laevigatum: Calilegua, $1100 \mathrm{msm}$, 12/11/2002. Zuloaga et al. 7548 (SI). Blechnum occidentale: Camino de Aguas Negras a Mesada 
de las Colmenas, 13/11/2002, 1100 msm, 234' 'S $64^{\circ}$ 52' W, Ramos Giacosa 104 (LP). Blechnum sprucei: Abra de las Cañas, de la Sota 4451 (LP). Blechnum squamipes: Aguada de Tigre, 2/2009, Ramos Giacosa et al. 37 (JUA, LP). Blechnum yungense: Camino hacia Abra de las Cañas, 2/2009, Ramos Giacosa et al. 60 (JUA, LP).

\section{CYATHEACEAE}

Alsophila odonelliana: Dpto. Ledesma, Parque Nacional Calilegua, Río de las Piedras, 2/10/1986, Iudica \& Ramadori 343 (SI).

\section{CYSTOPTERIDACEAE}

Cystopteris diaphana: Camino desde Monolito hacia Mesada de las Colmenas, $23^{\circ} 40^{\prime} 58^{\prime \prime} \mathrm{S} 64^{\circ}$ 54' 04" W 1720, m.s.m., 4/7/2010, Larsen 142 \& Arana (SI, RCV).

\section{DENNSTAEDTIACEAE}

Dennstaedtia globulifera: Zona pozos de petróleo yacimiento El Caimancito, 23/5/2011, Ganem et al. 14 (JUA, LP, RCV). Hypolepis poeppigii: Camino desde Monolito hacia Mesada de las Colmenas, $23^{\circ} 41^{\prime}$ 08' S 64'53' 47' W, 1616 m.s.m., 05/07/2010, Larsen 147 \& Arana (SI, $\mathrm{RCV})$.

\section{DRYOPTERIDACEAE}

Bolbitis serratifolia: Sendero Guaraní, 2/2009, Ramos Giacosa et al. 18 (JUA, LP). Ctenitis submarginalis: Calilegua, Capurro 229 (LIL). Dryopteris patula: Camino desde Monolito hacia Mesada de las Colmenas, $23^{\circ} 41^{\prime} 08^{\prime \prime} \mathrm{S} 64^{\circ}$ 53' 47” W, 1616 m.s.m., 5/7/2010, Larsen 146 \& Arana (SI, RCV). Dryopteris wallichiana: Camino desde Monolito hacia Mesada de las Colmenas, 24/5/2011, Ganem et al 36 (JUA, LP, RCV). Elaphoglossum crassipes: Aguada de Tigre, 2/2009, Ramos Giacosa et al. 67 (JUA, LP). Elaphoglossum gayanum: Camino de Abra de la Cañas a Mesada de las Colmenas, $23^{\circ} 41^{\prime} \mathrm{S}$ $64^{\circ} 54^{\prime} \mathrm{W}, 12 / 11 / 2002$, Ramos Giacosa 105 (LP). Elaphoglossum lindbergii: Camino desde Monolito hacia Mesada de las Colmenas, $23^{\circ} 41^{\text {' }}$ 08" S 64 53' 47" W, 1616 m.s.m., 5/7/2010, Larsen 149 \& Arana (SI, RCV). Elaphoglossum lorentzii : Aguada de Tigre, 2/2009, Ramos Giacosa et al. 62 (JUA, LP). Elaphoglossum piloselloides: Camino a Mesada de las Colmenas, 24/5/2011, Ganem et al 38 (JUA, LP, RCV). Elaphoglossum sellowianum: Aguada de Tigre, 25/5/2011, Ganem et al. 43 (JUA, LP, RCV). Elaphoglossum yungens: Camino de Mesada de las Colmenas a Abra de Cañas, de la Sota 4408 (LP). Megalastrum adenopteris: Camino a Mesada de las Colmenas, 24/5/2011, Ganem et al. 25 (JUA, LP, RCV). Megalastrum pulverulentum: Calilegua, 20/2/1998, Morrone et al. 2863 (SI). Polystichum montevidense: Camino a Mesada de las Colmenas, 24/5/2011, Ganem et al. 37 (JUA, LP, RCV). Polystichum platyphyllum var. platyphyllum: Sendero el Negrito, 2/2009, Ramos Giacosa et al. 43 (JUA, LP).

\section{EQUISETACEAE}

Equisetum bogotense: Camino al yacimiento de petróleo El Caimancito, 23/5/2011, Ganem et al. 5 (JUA, LP, RCV). Equisetum giganteum: Arroyo Aguas Negras, sendero a la Junta, Ahumada et al. 8515 (JUA).

\section{HYMENOPHYLLACEAE}

Didymoglossum reptans: Cerca de Aguada de Tigre, $23^{\circ} 41^{\prime} 03^{\prime}$ S $64^{\circ} 53^{\prime} 40^{\prime \prime} \mathrm{W}, 1630$ m.s.m., 05/07/10, Larsen $161 \&$ Arana (SI, RCV). Hymenophyllum capurroi: Aguada de Tigre, 02/2009, Ramos Giacosa et al. 30 (JUA, LP). Hymenophyllum crispum:Aguada de Tigre, $23^{\circ}$ 41'03" S 64 53' 40” W, 1630 m.s.m. 05/07/2010, Larsen 154 \& Arana (SI, RCV). Hymenophyllum polyanthos: Camino desde Monolito hacia Mesada de las Colmenas, $23^{\circ} 41^{\prime}$ 08" S 64 53' 47' W, 1616 m.s.m., 05/07/2010, Larsen 144 \& Arana (SI, RCV). Hymenophyllum. tunbridgense var. cordobense: Aguada de Tigre, 02/2009, Ramos Giacosa et al. 31 (JUA, LP).Vandenboschia angustata: Aguada de Tigre, 23 41'03" S 64 53' 40" W, 1630 m.s.m., 05/07/10, Larsen $152 \&$ Arana (SI, RCV).

\section{LYCOPODIACEAE}

Diphasiastrum thyoides: Camino de Abra de las Cañas a Mesada de las Colmenas, $23^{\circ} 41^{\prime} \mathrm{S}, 64^{\circ}$ 54'W, 1650 m.s.m., 12/11/ 2002, Ramos Giacosa 110 (LP). Lycopodium clavatum subsp clavatum: Camino de Abra de las Cañas a Mesada de las Colmenas, $23^{\circ} 41^{\prime}$ 'S $64^{\circ} 54^{\prime} \mathrm{W}, 1650$ m.s.m., 12/11/ 2002, Ramos Giacosa 109 (LP). Phlegmariurus phylicifolius: Camino a Mesada de las Colmenas, 
24/5/2011, Ganem et al 40 (JUA, LP, RCV). Phlegmariurus reflexus: Calilegua, 1670 m.s.m., 17/3/2009, Martínez \& Chambi 1819 (MCNS). Phlegmariurus saururus: Serranía de Calilegua, Cerro Hermoso, 3320 m.s.m., 19/2/1965, Fabris 5921 et Crisci \& Petriella (LP). Phlegmariurus sotae: Abra de las Cañas, de la Sota 4424 (LP).

\section{OPHIOGLOSSACEAE}

Botrychium schaffneri: Cerca de Monolito, ladera de montaña, 1641 m.s.m., 20/4/2008, Gutierrez et al. 615 (LP).

\section{POLYPODIACEAE}

Campyloneurum aglaolepis: Camino a Mesada de las Colmenas, 24/5/2011, Ganem et al 41 (JUA, LP, RCV). Campylonerurum nitidum: En cauce de arroyo bajo arbustos, 12/11/2002, Zuloaga et al 7546 (SI). Campyloneurum tucumanense: Arroyo Tres Cruces, 2/2009, Ramos Giacosa et al. 15 (JUA, LP). Microgramma squamulosa: Sendero Tataupá, 2/2009, Ramos Giacosa et al. 23 (JUA, LP). Pecluma filicula: Sendero que une el camino principal con Arroyo El Negrito (Sendero 4) $23^{\circ} 44^{\prime}$ 20" S 64 51' 14" W, 758 m.s.m., 4/7/2010, Larsen 131 Arana (SI, RCV). Pecluma oranense: Camino a Abra de las Cañas, 1200 m.s.m, 11/11/1975, Schiavone et al 11917c (LIL). Pecluma venturii: Aguada de Tigre, febrero 2009, Ramos Giacosa et al. 65 (JUA, LP). Phlebodium aureum: Quebrada del Arroyo del Medio, cerca del límite con el Parque Nacional Calilegua, 700-1000 m.n.m., Tolaba et al. 1866 (JUA). Pleopeltis macrocarpa: Abra de las Cañas, 1707 m.s.m, 1/12/1969, Legname \& Cuezzo 7250c (LIL). Pleopeltis minima: Sendero Tataupá, 2/2009, Ramos Giacosa et al. 22 (JUA, LP). Pleopeltis pleopeltidis: Aguada de Tigre, 2/2009, Ramos Giacosa et al. 34 (JUA, LP). Pleopeltis tweediana: Camino a Mesada de las Colmenas, 24/5/2011, Ganem et al 34 (JUA, LP, RCV). Serpocaulon gilliesii: Aguada de Tigre, $23^{\circ} 41^{\prime} 03^{\prime}$ " S 64 53' 40”' W, 1630 m.s.m., 05/07/2010, Larsen 157 \& Arana (SI, RCV).

\section{PTERIDACEAE}

Adiantopsis chlorophylla: Camino de Mesada de las Colmenas a Abra de las Cañas, de la Sota 4405 (LP). Adiantum digitatum: Serranía de Calilegua, Alto Calilegua, 18/2/1965, Fabris et al. 5780 (LIL). Adiantum lorentzii: Cerca del mirador, 4/7/2010, $23^{\circ} 45^{\prime} 28^{\prime \prime} \mathrm{S} 64^{\circ} 51^{\prime}$ ' $15^{\prime \prime} \mathrm{W} 680$ m.s.m, Larsen 115 \& Arana (SI, RCV). Adiantum pectinatum: Zona pozos de petróleo yacimiento El Caimancito, 23/5/2011, Ganem et al. 16 (JUA, LP, RCV). Adiantum poiretii: Camino al yacimiento El Caimancito, 23/5/2011, Ganem et al. 6 (JUA, LP, RCV). Adiantum pseudotinctum : Yacimiento El Caimancito, 23/5/2011, Ganem et al. 6A (JUA, LP, RCV). Adiantum raddianum: Mesada de las Colmenas, sendero de La Cascada, $1100 \mathrm{msm}$, 13/11/2002, Ramos Giacosa 113 (LP). Anogramma lorentzii: Forest of Calilegua, Bartlett 20370 (SI). Argyrochosma nivea var. flava: Along the road to the old coffe plantation, Bartlett 20378 (GH, US). Argyrochosma nivea var. tenera : Sierra de Calilegua, Abra de Cañas, Fabris 3468 (LP). Pteris cretica: Camino de Abra de las Cañas a Mesada de las Colmenas, $23^{\circ} 41^{\prime} \mathrm{S} 64^{\circ} 54^{\prime} \mathrm{W}, 1650$ m.s.m, 12/11/2002, Ramos Giacosa 121 (LP). Pteris deflexa: Mesada de las Colmenas, Fabris 3429 (LP). Pteris denticulata var. denticulata: Zona pozos de petróleo yacimiento El Caimancito, 23/5/2011, Ganem et al 9 (JUA, LP, RCV). Pteris exigua: Sendero Bosque del Cielo, 25/5/2011, Ganem et al 47 (JUA, LP, RCV). Pteris inermis: Camino desde Monolito hacia Mesada de las Colmenas, $23^{\circ} 40^{\prime}$ 58" S 64 54' 04" W, 1720 m.s.m., 4/7/2010, Larsen 135 \& Arana (SI, RCV). Pteris plumula: Camino de Ledesma a Valle Grande, $23^{\circ} 42^{\prime}$ S $64^{\circ} 51^{\prime} \mathrm{W}, 960$ m.s.m., 12/11/2002, Ramos Giacosa et al. 123 (LP). Cheilanthes poeppigiana: Serranía de Calilegua, Tolditos, $2600 \mathrm{msm}, 15-17 / 2 / 1965$, Fabris et al. 5738 (LIL). Doryopteris concolor: Mesada de las Colmenas, sendero de la Cascada, 1100 m.s.m, $23^{\circ} 41^{\prime}$ S 64 52'W, 13/11/2002, Ramos Giacosa 102 (LP). Doryopteris majestosa: Camino a Valle Grande, Mesada de las Colmenas, de la Sota 4481 (GH, LP, US) Doryopteris pentagona: Zona pozos de petróleo yacimiento El Caimancito, 23/5/2011, Ganem et al. 10 (JUA, LP, RCV). Hemionitis tomentosa: Sendero que une el camino principal con Arroyo El Negrito (Sendero 4), 23 44' 20" S 64 51' 14" W, 758 m.s.m., 4/7/2010, Larsen 119 \& Arana (SI, RCV). Trachypteris pinnata: Dpto. Ledesma, Parque Nacional Calilegua, Sierra de Calilegua, Venturi 5308 (US). Trismeria trifoliata: Camino de Aguas Negras a Mesada de las Colmenas, febrero de 2009, Ramos Giacosa et al (JUA, LP). 


\section{SALVINIACEAE}

Azollla filiculoides: Sendero La Lagunita, 2/2009, Ramos Giacosa et al. 29 (JUA, LP).

\section{SELAGINELLACEAE}

Selaginella microphylla: Arroyo Tres Cruces, 2/2009, Ramos Giacosa et al. 17 (JUA, LP). Selaginella novae-hollandiae: Camino a Mesada de las Colmenas, 24/5/2011, Ganem et al 39 (JUA, LP, RCV). Selaginella sellowii: Camino de Aguas Negras a Mesada de las Colmenas, 2/2009, Ramos Giacosa et al. 11 (JUA, LP).

\section{THELYPTERIDACEAE}

Macrothelypteris torresiana: Zona pozos de petróleo yacimiento El Caimancito, 23/5/2011, Ganem et al. 48 (JUA, LP, RCV). Thelypteris achalensis: Abra de las Cañas, de la Sota 4472 (LP). Thelypteris concinna: Sendero que une el camino principal con Arroyo El Negrito (Sendero 4) $23^{\circ} 44^{\prime} 20^{\prime}$ S $64^{\circ}$ 51' 14" W 758 m.s.m., 4/7/2010, Larsen 128 \& Arana (SI, RCV). Thelypteris grandis var. kunzeana: Borde de arroyo, 1150 m.s.m., 12/11/2002, Zuloaga et al 7551 (SI). Thelypteris hispidula: Zona pozos de petróleo yacimiento El Caimancito, 23/5/2011, Ganem et al. 19 (JUA, LP, RCV). Thelypteris interrupta: Zona pozos de petróleo yacimiento El Caimancito, 23/5/2011, Ganem et al. 21 (JUA, LP, RCV). Thelypteris jujuyensis: Camino de Mesada de las Colmenas a Abra de las Cañas, de la Sota 4412 (LP). Thelypteris nubicola: Abra de las Cañas, 6/12/1986, Zuloaga 2957 (SI). Thelypteris patens var. patens: Camino de Aguas Negras a Mesada de las Colmenas, 2/2009, Ramos Giacosa et al. 12 (JUA, LP). Thelypteris patens var. smithiana: Zona pozos de petróleo yacimiento El Caimancito, 23/5/2011, Ganem et al. 18 (JUA, LP, RCV).

\section{WOODSIACEAE}

Woodsia montevidensis: Serranía de Calilegua, Tolditos, Fabris et al. 5728 (LP).

\section{Discusión y Conclusiones}

En la República Argentina se reconocen 91 géneros de helechos y licofitas, con 402 taxones distribuidos principalmente en el NEA, NOA y la Patagonia (Ponce et al., 2002; Zuloaga et al., 2008).
Los datos obtenidos en el presente trabajo, 43 géneros y 103 taxones específicos e infraespecíficos de helechos y licofitas en el PN Calilegua, sustentan al NOA como una de las áreas de mayor diversidad de helechos y licofitas de Argentina, precedida por la provincia de Misiones (NEA), que posee 54 géneros con 175 taxa y seguida por la Patagonia, con cerca de 34 géneros y 90 taxa (Ponce et al., 2002) y las Sierras del centro de Argentina, con 42 géneros y 86 entidades (Arana \& Bianco, 2011).

En el PN Calilegua, las familias mejor representadas son: Pteridaceae (11 géneros), Dryopteridaceae (6 géneros) y Polypodiaceae (6 géneros). En cuanto al habito, el predominante es el terrestre $(70 \%)$, aunque se hallan una gran diversidad de epifitos $(20 \%)$ y en menor proporción especies saxicolas $(10 \%)$ y acuáticas $(1 \%)$.

Teniendo en cuenta las licofitas, se han encontrado nueve especies dentro del Parque, entre las cuales Phlegmariurus reflexus alcanza su límite de distribución austral. El patrón biogeográfico principal de la Flora de licofitas del PN Calilegua (Arana et al., 2011c) apoya la existencia del componente biótico ancestral neotropical de licofitas establecido por Arana et al. (2011b), con conexiones florísticas con las Sierras Pampeanas del centro argentino y las Subandinas. Además, la biota que comprende el área del PN Calilegua posee vinculaciones con la subregión Paranaense, compartiendo especies relativamente adaptadas a ambientes xéricos como Selaginella sellowii y Diphasiastrum thyoides, salvando así la diagonal árida formada por la subregión Chaqueña, que ocupa el norte y centro de la Argentina, sur de Bolivia, oeste y centro del Paraguay, y centro y noroeste del Brasil (Morrone, 2000a). Esta conexión también ha sido establecida para helechos del género Asplenium (Ganem et al., 2007) e incluso para grupos animales como las aves, las que aprovechan los bosques en galería a la largo de los cursos de agua representados por los ríos Bermejo, Pilcomayo, Paraguay y Paraná (Nores, 1992).

En el pasado reciente, posiblemente durante los períodos interglaciares del Cuaternario, la subregión Chaqueña era más húmeda que en la actualidad y de este modo las selvas Paranaense y de las Yungas cubrían una mayor superficie. Se considera así que los bosques en galería constituirían relictos que evidencian una distribución de bosques más amplia (Van der Hammen,1974), la que fue gradualmente 
fragmentada en dos partes, una noroeste (Yungas) y una sureste (Paranaense), separadas por la diagonal árida conformada por la Subregión Chaqueña (Morrone \& Coscarón. 1996; Morrone, 2000b).

Teniendo en cuenta los programas de conservación de la biodiversidad en la Argentina, el PN Calilegua resulta un área de sumo interés por su localización geográfica y difícil acceso, donde la flora y la fauna se hallan en general en muy buen estado de preservación.

En un trabajo reciente, Giudice et al. (2011) categorizaron doce taxones de helechos que crecen en el Parque entre las categorías 3 y 4 de acuerdo a su grado de amenaza; Pecluma oranense, Thelypteris nubicola, Alsophila odonelliana e Hymenophyllum capurroi, fueron categorizadas en nivel 4, por lo que los ambientes donde crecen estas plantas merecen una especial atención de protección.

Así, se consideran relevantes los datos aportados por los estudios de la flora y la fauna de este Parque ubicado dentro de las Yungas (Reserva de la Biosfera) y que contribuyan a planear la zonificación del área según el estado de conservación y de uso requerido, logrando así zonas de protección total y zonas de uso sostenible.

\section{Agradecimientos}

Los autores desean agradecer a la Administración de Parques Nacionales por los permisos cedidos para realizar esta investigación. A los guardaparques del Parque Nacional Calilegua por su colaboración y guía durante los viajes de campo.

Este trabajo fue financiado por subsidios de CONICET (PIP 878), UNLP (N 465 y N610) y UNJu (08/A115).

\section{Biblografía}

ARANA, M. D. \& C. A. BIANCO. 2011. Helechos y licofitas del centro de la Argentina. E- book publicado por Editorial UNRC.

ARANA, M., M.A. GANEM, M. L LUNA, J.P. RAMOS GIACOSA \& G. E. GIUDICE. 2011a. Diversidad y panbiogeografía de las Licofitas (Equisetopsida: Lycopodidae) del Parque Nacional Calilegua, Jujuy, Argentina. Bol Soc. Argent. Bot. (Supl.) 46: 180.

ARANA, M. D., J. J. MORRONE, M. PONCE \& A. J. OGGERO. 2011b. Licofitas (Equisetopsida:
Lycopodiidae) de las sierras centrales de Argentina: un enfoque Panbiogeográfico. Gayana Bot. 68: 14-21.

ARANA, M., J. J. MORRONE, M. A. GANEM, M. L. LUNA, J. P. RAMOS GIACOSA \& G. E. GIUDICE. 2011c. Diversidad y análisis panbiogeográfico de las licofitas (Equisetopsida: Lycopodiidae) del Parque Nacional Calilegua, Jujuy, Argentina. Iheringia (en prensa).

CABRERA, A. L. 1976. Territorios fitogeográficos de la República Argentina. En L. R. Parodi (ed.) Enciclopedia Argentina de Agricultura y Jardinería, ed. 2, Acme, Buenos Aires.

CABRERA, A. L. 1978. Especies nuevas o críticas del género Solanum de la provincia de Jujuy, Argentina. Hickenia 1:161-170

CABRERA, A.L. \& A.WILLINK. 1980. Biogeografía de América Latina. Serie Biología. Monog. OEA 13:1-122.

CHRISTENHUSZ, M. J.; X. ZHANG \& H. SCHNEIDER. 2011. A linear sequence of extant families and genera of lycophytes and ferns. Phytotaxa 19: 7-54

EZCURRA, C. 1994. Lista de especies de Acanthaceae coleccionadas en el NOA. Parque Nacional Baritú y Calilegua. Informe Administración de Parques Nacionales, Delegación Regional Noroeste.

GANEM, M. A, G. E. GIUDICE, M. L.LUNA \& E. R. DE LA SOTA. 2007. Revisión del grupo "Asplenium squamosum" en América. Candollea 62: 149- 156

GIUDICE, G. E, J. P. RAMOS GIACOSA, M. L. LUNA, C. MACLUF, M. PONCE, G. MARQUEZ \& E. R. DE LA SOTA. 2011 Evaluación preliminar del grado de amenaza de los helechos y licofitas de Argentina. Bol. Soc. Argent. Bot. 46: 151-161.

JOHNSON, A.E. 1998. Las orquídeas de los Parques Nacionales Baritú (Salta) y Calilegua (Jujuy). Informe Administración de Parques NacionalesDelegación Regional Noroeste.

KAPELLE, M. \& A.D. BROWN (Eds.). 2001. Bosques nublados del neotrópico. Instituto Nacional de Biodiversidad. Costa Rica.

LOMÁSCOLO, T, A. BROWN \& L. MALIZIA. 2010. Reserva de Biosfera de las Yungas. Ediciones subtropico. Fundación Proyungas.

LÓPEZ, G., L.I. FERRARO, R. VANNI \& O. POPOFF. 1998. Hongos y líquenes del Parque Nacional Calilegua, Departamento General San Martín, Provincia de Jujuy. Informe Administración de Parques Nacionales-Delegación Regional Noroeste.

MORRONE, J. J. 2000a. A new regional biogeography of the Amazonian subregion, mainly based on animal taxa. An. Inst. Biol. UNAM, ser. Zool. 71: 99-123.

MORRONE, J.J. 2000b. What is the Chacoan subregion? Neotropica 46: 51-68.

MORRONE, J. J. 2001. Biogeografía de América Latina y el Caribe. Manuales \& Tesis SEA, nro. 3, Sociedad 
Entomológica Aragonesa, Zaragoza.

MORRONE, J. J. \& M. C. COSCARÓN. 1996. Distributional patterns of the American Peiratinae (Heteroptera: Reduviidae). Zool. Med. Leiden 70: $1-15$.

MORRONE, O., F.O. ZULOAGA, J.F. PENSIERO, A.M. CIALDELlA \& N. DEGINANI. 1999. Relevamiento de plantas vasculares del Parque Nacional Calilegua (Jujuy). Informe Administración de Parques Nacionales-Delegación Regional Noroeste.

MUÑOZ, J.D., R.E. SÁNCHEZ \& D.F. ALE. 1993. Lista de especies coleccionadas en la primavera de 1993 en el Parque Nacional Calilegua por los estudiantes Ramón Eduardo Sanchez y Daniel Fernando Ale. Informe Administración de Parques NacionalesDelegación Regional Noroeste.

NORES, M. 1992. Bird speciation in subtropical South America in relation to forest expansion and retraction. The Auk 109(2): 346-357.

ØLLGAARD, B. 1992. Neotropical Lycopodiaceae-An overview. Ann. Missouri Bot. Gard. 79: 687-717.

PEROVIC, P.G., S. DE BUSTOS, A. TÁlamo, C. TRUCCO \& D. VÁZQUEZ. 2000. Informe del Relevamiento de Flora y Fauna en el Parque Nacional Calilegua y alrededores, Jujuy, Argentina. Monitoring and Modelling the Impacts of Changing Governments Policies on Biodiversity Conservation in the Andes. Proyecto Bioandes. First Annual Report.Unión Europea.

PONCE, M., K. MEHLTRETER \& E.R., DE LA SOTA, 2002. Análisis biogeográfico de la diversidad pteridofítica en Argentina y Chile continental. Revista Chilena Hist. Nat. 175: 703-717.

RIVERA, G. 1994. Lista de Bignonaceae encontradas en Parques Nacionales Calilegua, Baritú e Iguazú. Informe Administración de Parques NacionalesDelegación Regional Noroeste.

ROTMAN, A., O. AHUMADA, A. CARRANZA, L. ARMELLA, M. MALDONADO, H. SATO, N. PACO, J. ACOSTA, M. ALVAREZ, A. GANEM \& I. ZINGARIELLO. 2007. Relevamiento de las comunidades vegetales del Parque Nacional Calilegua, Jujuy. Argentina. Bol. Soc. Argent. Bot. 42 (Supl.): 160
ROTMAN, A., O AHUMADA, A. CARRANZA, N. PACO, H. SATO, M. ALVAREZ \& M.

A.GANEM. 2008a. Divesidad Vegetal del Parque Nacional Calilegua, Jujuy, Argentina. Congreso Nacional de Conservación de la Biodiversidad, Buenos Aires. Libro de Resumenes: 320.

ROTMAN, A., O AHUMADA, A. CARRANZA, N. PACO, H. SATO, M. ALVAREZ \& M. A. GANEM. 2008 b. Divesidad de Especies Vegetales del Parque Nacional Calilegua, Jujuy, Argentina. IV Congreso Iberoamericano de Ambiente y Calidad de Vida$5^{\circ}$ Congreso de Ambiente y Calidad de Vida, Catamarca, 22-26 de Septiembre de 2008.

SANSO, A.M. \& C. C. XIFREDA. 1995. El género Bomarea (Alstroemeriaceae) en Argentina. Darwiniana 33:315-336.

SOTA, E. R. DE LA. 1977. Pteridophyta. En A. Cabrera (dir.), Flora de Jujuy. Colecc. Ci. Inst. Nac. Tecnol. Agropecu. 13:1-275.

THIERS, B. M. (ed.). 2012. Index Herbariorum. New York Botanical Garden, New York. (http://sciweb. nybg.org/science2/ IndexHerbariorum.asp).

VAN DER HAMMEN, T. 1974. The Pleistocene changes of vegetation and climate in tropical South America. J. Biogeogr. 1:3-26.

WULFF, A. F., J. H. HUNZIKER \& A. ESCOBAR 1996. Estudios cariológicos en Compositae VII. Darwiniana 34: 213-231.

XIFREDA, C. C. 1996. Citas nuevas o críticas para la Flora Argentina II: Gloxinia gymnostoma y G. nematanthodes (Gesneriaceae). Darwiniana 34:383-388

YESILYURT, J.C. 2007.Doryopteris majestosa (Pteridaceae) a new species from South America. Amer.Fern Jour. 97:212-219.

ZULOAGA, F.O., O. MORRONE. \& M. J. BELGRANO (eds.). 2008. Catálogo de las plantas vasculares del Cono Sur. Vol. 1. Pteridophyta, Gymnospermae y Monocotyledonae. Monogr. Syst. Bot. Missouri Bot.l Gard. 107.

Recibido el 23 de agosto de 2012, aceptado el 7 de noviembre de 2012. 